\title{
Results of Intravitreal Anti-VEGF Injection in Choroidal Neovascularization Caused by Pathologies Other Than Age-Related Macular Degeneration
}

\section{Mehmet Ozveren}

Department of Ophthalmology, Edirne Sultan I. Murat State Hospital, Edirne, Turkey

\begin{abstract}
Objectives: The aim of this retrospective study was to evaluate the efficacy of the intravitreal injection of anti-vascular endothelial growth factor (anti-VEGF) agents to treat choroidal neovascularization (CNV) caused by a pathology other than exudative type age-related macular degeneration (AMD).

Methods: This was a retrospective study of 43 treatment naive eyes of 35 patients who had been diagnosed with CNV caused by a pathology other than exudative- type AMD and who underwent intravitreal injection of anti-VEGF agents. Primary and secondary outcome measures were the best corrected visual acuity (BCVA) and the central macular thickness (CMT).

Results: The mean patient age was $44.6 \pm 13$.I years. The mean number of injections was $3.3 \pm 1.8$. The mean logarithm of minimal angle of resolution BCVA at baseline and the $12^{\text {th }}$ month follow-up was $0.89 \pm 0.50$ and $0.73 \pm 0.57$, respectively $(p=0.120)$. In all, $44.2 \%$ of the eyes gained $\geq 15$ letters of BCVA, whereas $14 \%$ lost $\geq 15$ letters of BCVA. The mean CMT at baseline and the $12^{\text {th }}$ month follow-up was $38 I \pm I 2 I$ and $3 I I \pm 73$ microns, respectively $(p=0.00 I)$.

Conclusion: Stabilized functional and improved anatomic outcomes following intravitreal anti-VEGF agent injection for CNV unrelated to AMD were seen at the $12^{\text {th }}$ month of follow-up.

Keywords: Angioid streaks, anti-VEGF, idiopathic choroidal neovascularization.
\end{abstract}

\section{Introduction}

Choroidal neovascularization (CNV) occurs when choroidal vessels proliferate in the subretinal space or below the retinal pigment epithelium (RPE) and it is characterized by RPE detachment, subretinal and/or intraretinal leakage and/or bleeding, and disciform scarring (I).

It can be assumed that there is a risk of CNV development in any case where the integrity of Bruch's membrane or the RPE is impaired. Today, the most common cause of CNV is indisputably age-related macular degeneration (AMD), but $\mathrm{CNV}$ may also occur secondary to many other etiologies, such as pathological myopia, angioid streaks, uveitis, infec- tion, and traumatic Bruch's membrane-RPE defects, and idiopathic cases where no etiology can be detected $(2,3)$.

Vascular endothelial growth factor (VEGF) is known to play a key role in the pathogenesis of CNV (4). Numerous controlled, prospective studies investigating CNV associated with AMD have reported anti-VEGF agents as a highly effective and reliable treatment option (4). However, there are few controlled, prospective studies that have examined treatment with anti-VEGF agents in CNV due to other causes, given the relatively low incidence (3). The European Medicines Agency, the European Union agency in charge of the evaluation and supervision of medicinal products, has ap- 
proved ranibizumab for CNV of any cause, but the US Food and Drug Administration has approved ranibizumab only for CNV caused by AMD and pathological myopia $(5,6)$.

This study was an analysis of anatomical and functional changes in patients treated with intravitreal anti-VEGF therapy for CNV with a non-AMD etiology and an evaluation of the results.

\section{Methods}

The outpatient retina files of Prof. Dr. N. Reşat Belger of Beyoğlu Eye Training and Research Hospital were examined to identify patients who had received intravitreal ranibizumab and/or bevacizumab for the treatment of CNV unrelated to AMD between January 2013 and April 2016. The study was carried out in accordance with the Declaration of Helsinki and was approved by the Trakya University Faculty of Medicine Scientific Research Ethics Committee (no: 2019/477).

\section{Exclusion criteria:}

I. Other active or previous eye disease that may cause visual loss (other retinal diseases, corneal pathologies, uveitic sequelae, previous vitreoretinal surgery, etc.);

2. Eyes with CNV due to AMD, polypoidal choroidal vasculopathy, retinal angiomatous proliferation;

3. Uncontrolled systemic disease, an impaired bleeding profile, renal dysfunction, patients with a history of thromboembolic attacks, and women who were pregnant or nursing;

4. Patients who had previously been treated for $\mathrm{CNV}$ or who were determined to be treated concurrently with other agents, such as intravitreal or systemic steroids; and

5. Presence of follow-up data of fewer than 12 months.

Due to the retrospective nature of the study, there was no established protocol, but the treatment regimen routinely applied to this group of patients in the clinic is as follows:

At baseline and all follow-up visits, the best corrected visual acuity (BCVA) is evaluated with the Early Treatment Diabetic Retinopathy Study (ETDRS) chart, an anterior segment examination is performed with slit lamp biomicroscopy, intraocular pressure is measured with a Goldman applanation tonometer, a fundus examination is performed with a 90D non-contact slit-lamp lens. Fundus fluorecein angiography (Heidelberg retinal angiography) is performed before a decision is made about an injection. Optical coherence tomography (OCT; Spectralis; Heidelberg Engineering, Heidelberg, Germany) is performed at baseline and all follow-up visits. The first anti-VEGF injection is administered within a week after diagnosis. Post-injection follow-up visits are scheduled at day I and month I. If signs of CNV activity are detected at follow-up, anti-VGEF treatment is repeated. If no CNV activity is observed, another injection is not recommended and subsequent follow-up is scheduled for I month. However, follow-up intervals in this study were longer than planned due to both the intense workload of the clinic and factors related to patient compliance. Therefore, only the data of the $3^{\text {rd }}, 6^{\text {th }}, 9^{\text {th }}$, and $12^{\text {th }}$ months were used, rather than the data from each month.

\section{The criteria used to assess CNV activity and re-in-} jection:

I. Decrease in BCVA by 5 letters on an ETDRS chart;

2. An increase in central macular thickness (CMT) of 100 microns or more compared with the prior examination;

3. New subretinal hemorrhage foci; and

4. Intra-subretinal fluid development/presence.

Patient demographic characteristics and the CMT, BCVA, and number of injections were evaluated retrospectively. Since many patients had switched between ranibizumab and bevacizumab, once or multiple times, the results could not been presented on the basis of anti-VEGF agents. The BCVA values were provided using the logarithm of minimal angle of resolution (LogMAR) unit to facilitate comparison with the LogMAR values in similar studies. In addition, based on previous studies, the percentage of patients with $\geq 15$ letter gain, and $\geq 15$ letter loss was presented. The mean, SD, and frequency values were used as descriptive statistics. Distribution of the variables was assessed using the Kolmogorov-Smirnov test. Repeated measures analysis of variance (ANOVA) was used to compare quantitative data of different time points within the group, and then a paired-t test was used for binary comparisons, if required. One-way ANOVA or the KruskalWallis test was applied for comparisons of quantitative data between groups, and an independent sample t-test or the Mann-Whitney $U$ test was used for binary comparisons, as needed. A chi-square test was used to analyze the qualitative data. IBM SPSS Statistics for Windows, Version 21.0 software (IBM Corp., Armonk, NY, USA) was used for the data analysis. No statistical analysis of traumatic retinal tear was performed in this study due to only I subject.

\section{Results}

The study included 43 eyes of 35 patients diagnosed with CNV unrelated to AMD. There were 18 (5I.4\%) female patients and $17(48.6 \%)$ male patients. The mean age of the patient group was $44.6 \pm 13.1$ years. The mean number of anti-VEGF injections in 12 months was $3.3 \pm 1.8$. CNV etiologies of the eyes and the mean BCVA values in logMAR units at baseline, and the $3^{\text {rd }}, 6^{\text {th }}, 9^{\text {th }}$, and $12^{\text {th }}$ month are shown in Table $I$.

The change in logMAR BCVA value was not statistically significant over the course of the baseline, $3^{\text {rd }}, 6^{\text {th }}, 9^{\text {th }}$, and $12^{\text {th }}$ month follow-up visits when all of the cases were evaluated together or in the etiologic subgroups $(p>0.05)$. There was no significant difference between etiologic groups in the 
Table I. The mean BCVA value in logMAR units according to etiologic group

\begin{tabular}{lccccccc} 
& Number of eyes & Baseline & $\mathbf{3}^{\text {rd }}$ month & $\mathbf{6}^{\text {th }}$ month & $\mathbf{9}^{\text {th }}$ month & I2 ${ }^{\text {th }}$ month & $\mathbf{P}^{*}$ \\
\hline Idiopathic & 8 & $0.98 \pm 0.61$ & $0.70 \pm 0.59$ & $0.60 \pm 0.53$ & $0.65 \pm 0.57$ & $0.58 \pm 0.51$ & 0.172 \\
Angioid streaks & 23 & $0.91 \pm 0.50$ & $0.83 \pm 0.66$ & $0.78 \pm 0.62$ & $0.80 \pm 0.56$ & $0.79 \pm 0.67$ & 0.554 \\
Type 2 JFT & 2 & $0.48 \pm 0.24$ & $0.46 \pm 0.20$ & $0.63 \pm 0.57$ & $0.63 \pm 0.57$ & $0.64 \pm 0.57$ & 0.860 \\
Pathologic myopia & 6 & $0.88 \pm 0.54$ & $0.87 \pm 0.67$ & $0.81 \pm 0.52$ & $0.82 \pm 0.47$ & $0.74 \pm 0.34$ & 0.805 \\
Multifocal choroiditis & 2 & $1.00 \pm 0.42$ & $0.72 \pm 0.81$ & $0.76 \pm 0.76$ & $0.84 \pm 0.63$ & $0.84 \pm 0.63$ & 0.500 \\
Tear in Bruch's membrane & $\mathrm{I}$ & 1.00 & 0.90 & 0.79 & 0.69 & 0.60 \\
Total study group & 43 & $0.89 \pm 0.50$ & $0.79 \pm 0.61$ & $0.74 \pm 0.56$ & $0.76 \pm 0.52$ & $0.73 \pm 0.57$ & 0.120 \\
\hline
\end{tabular}

*Repeated measures analysis of variance. BCVA: Best corrected visual acuity; JFT: Juxtafoveal telangiectasia.

baseline logMAR BCVA $(p=0.809)$ and $12^{\text {th }}$ month logMAR BCVA ( $p=0.967)$.

Table 2 illustrates the letter gain/loss classification at the $12^{\text {th }}$ month according to etiologic group. When the total study group was analyzed, it was found that 37 eyes (86\%) had lost fewer than 15 letters and the vision gain was 15 or more letters for 19 eyes (44.2\%).

The mean CMT values at baseline, and the $3^{\text {rd }}, 6^{\text {th }}, 9^{\text {th }}$, and $12^{\text {th }}$ months are shown in Table 3 . When the total study group was analyzed, the mean CMT value at baseline was significantly higher than that observed at the $3^{\text {rd }}$ month $(p=0.007), 6^{\text {th }}$ month $(p=0.014), 9^{\text {th }}$ month $(p=0.001)$, or $12^{\text {th }}$ month $(p=0.00 \mathrm{I})$. No significant difference was found between the $3^{\text {rd }}, 6^{\text {th }}, 9^{\text {th }}$, and $12^{\text {th }}$ month CMT values $(p=0.182)$.
There was no significant change between the baseline, and the $3^{\text {rd }}, 6^{\text {th }}, 9^{\text {th }}$, and $12^{\text {th }}$ month CMT values in groups defined by angioid streaks, multifocal choroiditis, pathologic myopia, and type 2 juxtafoveal telangiectasia $(p>0.05)$. In the idiopathic group, however, the initial CMT value was significantly higher than that of the $9^{\text {th }}$ month $(p=0.004)$ and the $12^{\text {th }}$ month $(p=0.002)$ CMT values. There was no statistically significant difference between the etiologic groups in the baseline $(p=0.286)$ or $12^{\text {th }}$ month CMT values $(p=0.775)$.

The number of visits and injections according to the etiology is shown in Table 4. The mean number of visits and injections in the first 12 months was $6.4 \pm 2.2$ and $3.2 \pm 1.7$, respectively. There was no significant difference in terms of either the number of visits $(p=0.254)$ or the number of injec-

Table 2. The letter gain/loss according to etiologic group

\begin{tabular}{|c|c|c|c|c|c|c|c|c|}
\hline & $\begin{array}{l}\text { Total study } \\
\text { group, (\%) }\end{array}$ & Idiopathic, (\%) & $\begin{array}{c}\text { Angioid } \\
\text { streaks, (\%) }\end{array}$ & $\begin{array}{c}\text { Type } 2 \\
\text { JFT, (\%) }\end{array}$ & $\begin{array}{l}\text { Pathologic } \\
\text { myopia, (\%) }\end{array}$ & $\begin{array}{c}\text { Multifocal } \\
\text { choroiditis, (\%) }\end{array}$ & $\begin{array}{l}\text { Tear in Bruch's } \\
\text { membrane, (\%) }\end{array}$ & $\mathbf{p}^{*}$ \\
\hline$<15$ letter loss & $37(86)$ & $8(100)$ & $19(82.6)$ & $2(66.7)$ & $5(83.3)$ & $2(100)$ & I (100) & 0.598 \\
\hline$\geq 15$ letter gain & $19(44.2)$ & $4(50)$ & $9(39.1)$ & I (33.3) & $3(50)$ & I (50) & I (100) & 0.966 \\
\hline
\end{tabular}

*Chi square test; JFT: Juxtafoveal telangiectasia.

Table 3. Mean CMT value at baseline, $3^{\text {rd }}, 6^{\text {th }}, 9^{\text {th }}$, and $12^{\text {th }}$ months

\begin{tabular}{|c|c|c|c|c|c|c|}
\hline & Baseline & $3^{\text {rd }}$ month & $6^{\text {th }}$ month & $9^{\text {th }}$ month & $12^{\text {th }}$ month & p* \\
\hline Angioid streaks & $358 \pm 96$ & $326 \pm 78$ & $334 \pm 98$ & $317 \pm 86$ & $308 \pm 80$ & 0.250 \\
\hline Type 2 JFT & $346 \pm 25$ & $279 \pm 20$ & $285 \pm 21$ & $279 \pm 17$ & $272 \pm 6$ & 0.189 \\
\hline Pathologic myopia & $361 \pm 135$ & $339 \pm 107$ & $362 \pm 127$ & $352 \pm 97$ & $346 \pm 95$ & 0.800 \\
\hline Multifocal choroiditis & $468 \pm 256$ & $262 \pm 108$ & $253 \pm 75$ & $284 \pm 76$ & $316 \pm 62$ & 0.147 \\
\hline Total study group & $38| \pm| 2 \mid$ & $331 \pm 100$ & $323 \pm 92$ & $310 \pm 79$ & $311 \pm 73$ & $<0.05$ \\
\hline
\end{tabular}


Table 4. The number of visits and injections according to etiologic group

\begin{tabular}{lcccccccc} 
& $\begin{array}{c}\text { Total study } \\
\text { group }\end{array}$ & Idiopathic & $\begin{array}{c}\text { Angioid } \\
\text { streaks }\end{array}$ & $\begin{array}{c}\text { Type 2 JFT } \\
\end{array}$ & & $\begin{array}{c}\text { Pathologic } \\
\text { myopia }\end{array}$ & $\begin{array}{c}\text { Multifocal } \\
\text { choroiditis }\end{array}$ & $\begin{array}{c}\text { Tear in Bruch's } \\
\text { membrane }\end{array}$ \\
\hline Number of visits & $6.4 \pm 2.2$ & $7.0 \pm 2.8$ & $5.9 \pm 2.1$ & $6.0 \pm 1.7$ & $6.1 \pm 1.4$ & $9.0 \pm 2.8$ & 10 & 0.254 \\
Number of injections & $3.3 \pm 1.8$ & $3.2 \pm 2.3$ & $3.0 \pm 1.55$ & $2.6 \pm 1.5$ & $3.8 \pm 2.1$ & $5.5 \pm 0.7$ & 3 \\
\hline
\end{tabular}

*One-way analysis of variance; JFT: Juxtafoveal telangiectasia.

tions $(p=0.509)$ between the different etiologies.

No ocular or systemic adverse events were recorded that were caused by the injections.

\section{Discussion}

Unlike AMD, the causes of CNV were seen at a much earlier age in this study; the mean age of the patients was $44.60 \pm 13.1$ I years. Similar studies have reported a mean age of 44.9-54 years $(4,7)$.

Cohen et al. (4) investigated 363 patients with CNV who were younger than 50 years of age. The etiology was pathologic myopia in 62\%, idiopathic in 17\%, pseudo-ocular histoplasmosis syndrome in $12 \%$, angioid streaks in $5 \%$, and traumatic or inflammatory disorders in $4 \%$ of the cases. In our study, the rate of angioid streaks $(53.5 \%)$ was much higher and the rate of pathologic myopia (14\%) was lower. Similarly to our results, other studies have reported lower rates for myopic patients (8). The difference in the prevalence of myopia between countries may be the underlying cause of conflicting results. In some studies, the incidence of ocular histoplasmosis has been shown to be high, while others have reported a high multifocal choroiditis incidence. It is difficult to distinguish between presumed ocular histoplasmosis and multifocal choroiditis, which may have led to incidence differences in these 2 entities between studies. There were no patients with ocular histoplasmosis syndrome in this study, but 2 patients with uveitis diagnosed as multifocal choroiditis were included. Differences in the exclusion criteria of the studies and the small number of patients due to the rare nature of the disease seem to be the most likely explanation for significant etiologic differences between studies.

There is strong evidence indicating that the visual prognosis of myopic CNV without treatment is very poor as a result of chorioretinal atrophy developing around the CNV (9). It has been reported that CNV due to angioid streaks has a very poor course without treatment, and laser and photo dynamic treatment (PDT) treatment have also been reported to result in some vision loss, although the results vary according to the study $(8,10)$. CNV may cause severe visual loss in patients with multifocal choroiditis, but visual stabilization has been achieved with PDT treatment (9). Ho et al. (II) presented follow-up data of untreated idiopathic subfoveal CNV. They reported that $95 \%$ of the patients had a result of the same or better visual acuity in comparison with the baseline, and that lesions smaller than I disc area in size had a better prognosis.

In the ANCHOR (Ranibizumab versus Verteporfin for Neovascular Age-Related Macular Degeneration) and MARINA (The Minimally Classic/Occult Trial of the Anti-VEGF Antibody Ranibizumab in the Treatment of Neovascular AMD) studies, injections were administered every month for 12 months, while in the PrONTO (Prospective OCT Imaging of Patients with Neovascular AMD Treated with Intra-Ocular Lucentis) study, monthly exams were performed after 3 consecutive monthly injections; re-injection was performed when activity was detected. The visual results reported in the 3 studies were consistent (12-14). Furthermore, no difference in efficacy was reported between injections every month for 12 months and monthly 3 consecutive injections followed by pro re nata (PRN) treatment in a prospective study evaluating application strategies for the treatment of non-AMD CNV with ranibizumab, (I5). PRN has been the generally preferred strategy from the outset in several studies examining the treatment of non-AMD CNV $(5,10)$.

Case series reporting the results of ranibizumab $(7,8,10$, 16), ziv-aflibercept (17), and bevacizumab (18) treatment for CNV unrelated to AMD have observed a $\geq 15$ letter visual acuity gain rate of $36-57.1 \%$. A $<15$ letter vision loss rate of $90.5-100 \%$ has been reported. Many studies in this area have reported a significant reduction in the CMT with anti-VEGF treatment $(8,10,17,18)$. In a significant fraction of these studies, the patients had previously received other treatments for $\mathrm{CNV}$ or had received concurrent treatments during the study, which could affect treatment results. In addition, the length of follow-up varies considerably between and within the studies, which is a handicap for comparisons $(8,10,17,18)$.

The MINERVA study was a randomized, sham-controlled, double-blind, multicenter study to evaluate the efficacy and safety of ranibizumab in the treatment of CNV unrelated to AMD or pathologic myopia. The study design included baseline administration of ranibizumab and then as needed based on evidence of disease activity in I group, and a sham injection was administered to another group. At the end of the primary endpoint at 2 months, the ranibizumab group 
had an average gain of 9.5 letters, while the sham group had a loss of 0.4 letters; the ranibizumab group was found to have significantly better results in terms of efficacy. At month 2 and thereafter, ranibizumab was administered to all of the patients when needed and gains of II and 9.3 letters at 12 th month were reported in the ranibizumab and sham groups, respectively. The mean number of injections in the ranibizumab arm over a 12-month period was 5.8. In the 12 th month, $48.5 \%$ of the patients in the ranibizumab group gained $\geq 15$ letters, while only $2.7 \%$ of the patients showed a visual loss of $\geq 15$ letters. More successful results have been reported in idiopathic and angioid streaks subgroups (5).

In this study, a loss of $<15$ letters was detected in 37 eyes (86\%) at the conclusion of I year of follow-up. In 19 eyes $(44.2 \%)$, the vision gain was found to be $\geq 15$ letters. $A$ vision loss of $\geq 15$ letters was observed in 6 eyes (I4\%). Our results are comparable to those of the MINERVA study and other case series. In other research, the mean number of injections per year was 3.5-4.8, and in the MINERVA study it was $5.8(5,8,10,17,18)$. In this study, a mean of $3.2 \pm 1.7$ injections were performed in 12 months. While the average number of visits was 6.4 in this study, there were 13 fixed visits in the MINERVA study (5). We believe that some delay in both the determination of disease activity and providing the injection due to hospital and patient-related factors under real-life conditions explains these differences in results compared with a controlled clinical trial.

Studies investigating the efficacy of ranibizumab (19) and bevacizumab (20-22) treatment for CNV due to angioid streaks have reported a $\geq 15$ letter visual acuity gain rate ranging from $1 \mathrm{I} .4-72.7 \%$ of the eyes and $\mathrm{a} \geq 15$ letter visual acuity loss rate ranging from $0-34.8 \%$. Most of these studies included typical biases such as prior treatment, concurrent treatment, and different follow-up periods. In this study, a $\geq 15$ letter vision gain was seen in $39.1 \%$ of the eyes, and vision loss of $\geq 15$ letters was observed in $17.4 \%$.

Studies investigating the efficacy of ranibizumab (23) and bevacizumab (23-25) treatment of idiopathic CNV have reported visual acuity gain rates of $\geq 15$ letters ranging from $53.3-60 \%$ and $\geq 15$ letter visual acuity loss rates ranging from $0-6 \%$. The cited studies found that anti-VEGF treatment resulted in significantly increased visual acuity and decreased CMT. Anti-VEGF treatment has also been observed to be superior to PDT (23). Again, typical biases, such as prior treatment, concurrent treatment, and different lengths of follow-up were present. In this study, a $\geq 15$ letter vision gain was achieved in $50 \%$ of the eyes and no patient had a vision loss of $\geq 15$ letters.

The randomized, multicenter RADIANCE study compared the efficacy of ranibizumab and PDT in the treatment of myopic CNV and the results indicated that anti-VEGF administration was superior to PDT. It was also observed that there was no significant difference in the results of patients who received a single dose of ranibizumab and then PRN versus those who received 2 consecutive monthly injections followed by PRN strategy. At the $12^{\text {th }}$ month, $51.7 \%$ of the patients in the group who received the initial single dose of ranibizumab had a visual acuity increase of $\geq 15$ letters and there was a mean of 2 injections (26). In the REPAIR study (Ranibizumab for trEatment of CNV secondary to Pathological myopia: An. Individualized Regimen), which was a multicenter singlearm trial to investigate the effect of ranibizumab in myopic CNV, patients were initially given I injection and then a PRN strategy was pursued. There was a mean of 3.6 injections and the mean gain in letters was reported to be 13.8 at the $12^{\text {th }}$ month. While $36.9 \%$ of the patients had a visual acuity gain of $\geq 15$ letters, $1.5 \%$ had a visual loss of $\geq 15$ letters. In addition, a significant decrease in CMT was observed at $12^{\text {th }}$ months compared with the baseline values (27). Our results may be misleading since the number of patients with myopic CNV in our study was much smaller than in reports in the literature. In our study, there was no significant change in visual acuity or macular thickness parameters between the $12^{\text {th }}$ month and the starting point. However, at the $12^{\text {th }}$ month, $50 \%$ of our patients had a $\geq 15$ letter vision gain. In $33.3 \%$ of the patients, a vision loss of $\geq 15$ letters was observed. There was a mean of 3.8 injections. Although the initial central retinal thickness was similar in the REPAIR and RADIANCE studies and our study, the initial visual acuity values of 0.5-0.6 logMAR in those studies may be a sign of residual visual capacity of the patients included in the studies, which may explain the limited the visual gain in our study $(26,27)$.

The limitations of this study include a limited sample size, the retrospective design, the lack of a control arm, and the inclusion of patients treated with bevacizuamab and/or ranibizumab.

\section{Conclusion}

Our study determined that anti-VEGF treatment was an effective treatment option in the treatment of CNV unrelated to AMD that provides anatomic improvement and visual stability.

\section{Disclosures}

Ethics Committee Approval: The study was carried out in accordance with the Declaration of Helsinki and was approved by the Trakya University Faculty of Medicine Scientific Research Ethics Committee (no: 2019/477).

Peer-review: Externally peer-reviewed.

Conflict of Interest: None declared.

\section{References}

I. Grossniklaus HE, Green WR. Pathologic findings in pathologic myopia. Retina 1992;12:127-33. [CrossRef]

2. Grossniklaus HE, Green WR. Choroidal neovascularization. 
Am J Ophthalmol. 2004;137:496-503. [CrossRef]

3. Stuart A, Ford JA, Duckworth S, Jones C, Pereira A. Anti-VEGF therapies in the treatment of choroidal neovascularisation secondary to non-age-related macular degeneration: a systematic review. BMJ Open 2015;5:e007746. [CrossRef]

4. Cohen SY, Laroche A, Leguen Y, Soubrane G, Coscas GJ. Etiology of choroidal neovascularization in young patients. Ophthalmology 1996; 103:124I-4. [CrossRef]

5. Lai TYY, Staurenghi G, Lanzetta P, Holz FG, Melissa Liew SH, Desset-Brethes S, et al. Efficacy And Safety Of Ranibizumab For The Treatment Of Choroidal Neovascularization Due To Uncommon Cause: Twelve-Month Results of the MINERVA Study. Retina 20|8;38: I464-77. [CrossRef]

6. Summary of Product Characteristics : Lucentis $10 \mathrm{mg} / \mathrm{mL}$ solution for injection. European Medicines Agency. Available at: http://ec.europa.eu/health/documents/community-register/2016/2016 I I I4136324/anx_136324_en.pdf. Accessed May $3,2020$.

7. Troutbeck R, Bunting R, van Heerdon A, Cain M, Guymer R. Ranibizumab therapy for choroidal neovascularization secondary to non-age-related macular degeneration causes. Clin Exp Ophthalmol 20I2;40:67-72. [CrossRef]

8. Chang LK, Spaide RF, Brue C, Freund KB, Klancnik JM Jr, Slakter JS. Bevacizumab treatment for subfoveal choroidal neovascularization from causes other than age-related macular degeneration. Arch Ophthalmol 2008;126:94I-5. [CrossRef]

9. Ohno-Matsui K, Yoshida T. Myopic choroidal neovascularization: natural course and treatment. Curr Opin Ophthalmol 2004; I5:197-202. [CrossRef]

10. Carneiro AM, Silva RM, Veludo MJ, Barbosa A, Ruiz-Moreno JM, Falcão MS, et al. Ranibizumab treatment for choroidal neovascularization from causes other than age-related macular degeneration and pathological myopia. Ophthalmologica 20I I;225:8I-8. [CrossRef]

II. Ho AC, Yannuzzi LA, Pisicano K, DeRosa J. The natural history of idiopathic subfoveal choroidal neovascularization. Ophthalmology 1995; 102:782-9. [CrossRef]

12. Brown DM, Kaiser PK, Michels M, Soubrane G, Heier JS, Kim RY, et al. Ranibizumab versus verteporfin for neovascular age-related macular degeneration. N Engl J Med 2006;355: I432-44.

13. Fung AE, Lalwani GA, Rosenfeld PJ, Dubovy SR, Michels S, Feuer WJ, et al. An optical coherence tomography-guided, variable dosing regimen with intravitreal ranibizumab (Lucentis) for neovascular age-related macular degeneration. Am J Ophthalmol 2007; 143:566-83. [CrossRef]

14. Rosenfeld PJ, Brown DM, Heier JS, Boyer DS, Kaiser PK, Chung $\mathrm{CY}$, et al. Ranibizumab for neovascular age-related macular degeneration. N Engl J Med 2006;355: 1419-3I. [CrossRef]

15. Heier JS, Brown D, Ciulla T, Abraham P, Bankert JM, Chong S, et al. Ranibizumab for choroidal neovascularization secondary to causes other than age-related macular degeneration: a phase I clinical trial. Ophthalmology 20 I I; I 8: I | |-8. [CrossRef]

16. Erol MK, Ozdemir O, Coban DT, Ceran BB, Bulut M. Ranibizumab treatment for choroidal neovascularization secondary to causes other than age-related macular degeneration with good baseline visual acuity. Semin Ophthalmol 2014;29:108-13.

17. Braimah IZ, Stewart M, Videkar C, Dedhia CJ, Chhablani J. Intravitreal ziv-aflibercept for the treatment of choroidal neovascularisation associated with conditions other than age-related macular degeneration. Br J Ophthalmol. 2017;10I:120I-5.

18. Chen L, Miller JW, Vavvas D, Kim IK. Anti-Vascular Endothelial Growth Factor Monotherapy Versus Combination Treatment With Photodynamic Therapy For Subfoveal Choroidal Neovascularization Secondary To Causes Other Than Age-Related Macular Degeneration. Retina 201 I;31:2078-83. [CrossRef]

19. Mimoun G, Tilleul J, Leys A, Coscas G, Soubrane G, Souied $\mathrm{EH}$. Intravitreal ranibizumab for choroidal neovascularization in angioid streaks. Am J Ophthalmol 2010;150:692-700. [CrossRef]

20. Alagöz C, Alagöz N, Özkaya A, Çelik U, Turan MF, Yazici AT, et al. Intravitreal Bevacizumab In The Treatment Of Choroidal Neovascular Membrane Due To Angioid Streaks. Retina 2015;35:200I-10. [CrossRef]

21. Neri P, Salvolini S, Mariotti C, Mercanti L, Celani S, Giovannini A. Long-term control of choroidal neovascularisation secondary to angioid streaks treated with intravitreal bevacizumab (Avastin). Br J Ophthalmol 2009;93:155-8. [CrossRef]

22. Battaglia Parodi M, lacono P, La Spina C, Berchicci L, Scotti F, Leys $\mathrm{A}$, et al. Intravitreal bevacizumab for nonsubfoveal choroidal neovascularization associated with angioid streaks. Am J Ophthalmol 2014;157:374-7. [CrossRef]

23. Kang HM, Koh HJ. Intravitreal anti-vascular endothelial growth factor therapy versus photodynamic therapy for idiopathic choroidal neovascularization. Am J Ophthalmol 2013;155:713-9.

24. Kim H, Lee K, Lee CS, Byeon SH, Lee SC. Subfoveal choroidal thickness in idiopathic choroidal neovascularization and treatment outcomes after intravitreal bevacizumab therapy. Retina 2015;35:48I-6. [CrossRef]

25. Mandal S, Garg S, Venkatesh P, Mithal C, Vohra R, Mehrotra A. Intravitreal bevacizumab for subfoveal idiopathic choroidal neovascularization. Arch Ophthalmol 2007; I 25:1487-92. [CrossRef]

26. Wolf S, Balciuniene VJ, Laganovska G, Menchini U, Ohno-Matsui $\mathrm{K}$, Sharma T, et al. RADIANCE: a randomized controlled study of ranibizumab in patients with choroidal neovascularization secondary to pathologic myopia. Ophthalmology 2014;121:682-92. [CrossRef]

27. Tufail A, Narendran N, Patel PJ, Sivaprasad S, Amoaku W, Browning $A C$, et al. Ranibizumab in myopic choroidal neovascularization: the 12-month results from the REPAIR study. Ophthalmology 2013;120:1944-5. [CrossRef] 